\title{
PREDATOR AVOIDANCE BEHAVIORS AND WEB DEFENSIVE STRUCTURES IN THE ORB WEAVERS ARGIOPE AURANTIA AND ARGIOPE TRIFASCIATA (ARANEAE, ARANEIDAE)*
}

\author{
By Wayne W. Tolbert \\ Graduate Program in Ecology, University of Tennessee, \\ Knoxville, Tenn. 37916
}

\section{INTRODUCTION}

Many spiders spend virtually all of their lives on orb webs. Orb weavers are known from all continents except Antarctica, as well as many island groups. In addition to a cosmopolitan distribution, individual species are locally abundant in a variety of habitats. The diversity of this assemblage is also quite pronounced with 2500 species of Araneidae, I50 species of Uloboridae and over a dozen species of Tetragnathidae recognized (Levi and Levi, I968). Since the uloborids are not closely related to the other two orb-weaving families, the ability to construct orb webs probably evolved independently (Kaston, 1966). It is generally conceded that the orb web is a highly developed type of spider web (Kaston, 1964) which allows exploitation of aerial food sources (insects and other invertebrates), not readily available to other spiders, with a minimum of wind damage to the web. Despite the apparent success of this web type, it allows exposure of its occupant not only to the exigencies of the abiotic environment but to predators and parasites as well. Orb weavers fall prey to wasps (Muma and Jeffers, 1945; Kurczewski, 1963; Kurczewski and Kurczewski, 1968a, 1968b and Dorris, 1970), birds (Robinson and Robinson, I970 and Royama, 1970) and other spiders (Enders, 1974). Vertebrate predators such as frogs, toads and lizards may be locally important.

While predator avoidance behaviors have been examined in several animal groups (Tinbergen, 1969 and Eibl-Eibesfeldt, 1970), no formal study has been completed on spiders. Several earlier spider workers (Bristowe, I94I and Comstock, 1940) noted that web flexing, dropping from the web, color changes and other behaviors were elicited when spiders were disturbed. Gertsch (1949) listed some escape responses of the line weaver Pholcus phalangioides

*Manuscript received by the editor January 25, 1975 
(Fuesslin) and Savory (1964) discussed web flexing, dropping from the web and death feigning as reflex responses. Robinson and Robinson (1973) ascribed a defensive function to movement by Nephila maculata (Fabricius) up the web, sometimes onto nearby vegetation. Eberhard (1970) was able to relate dropping from the retreat by Araneus cornutus (Clerck) to attack by predatory wasps.

This study identifies some of the components of predator avoidance behavior in Argiope aurantia Lucas and A. trifasciata (Forskal), which are known as the black and yellow garden spider and banded garden spider respectively. The frequency of occurrence of various components is determined for both species; response variation with instar and direction of approach by a predator model is assessed. In addition, specific aspects of web architecture, barrier webs and stabilimenta, are examined and the possible relationships to predator avoidance behaviors are discussed.

I wish to thank Mr. David Stair for field assistance, my wife Ginny for preparation of the figures and Drs. Susan E. Riechert and Gordon M. Burghardt for critically reviewing the manuscript.

Financial support was provided by the NSF (grant BMS 74I 7602) and by the Graduate Program in Ecology at the University of Tennessee, Knoxville.

\section{Methods}

During the spring of 1974 a field study of mortality factors and migration characteristics of the orb weaver Argiope aurantia was initiated in an overgrown, abandoned pasture $2 \mathrm{mi}$. west of Glendale, Loudon County, Tennessee. While engaged in this research, I frequently observed encounters between the two Argiope species, aurantia and trifasciata, and salticid spiders, Phidippus audax (Hentz) and $P$. clarus (Keyserling). Some attacks by the salticids were successful, some resulted only in leg losses by Argiope and some were unsuccessful. Due to the brevity of these encounters I rarely observed complete sequences. Thus, in order to obtain quantitative evidence concerning the nature of predator avoidance in Argiope, an artificial predator was employed. For the purposes of this study, a standard-sized lead pencil with rubber eraser (roughly the crosssectional diameter of the salticids) was used to simulate an invertebrate predator. Spiders were approached with the eraser end of a pencil from either the ventral surface, in which case the hub of the web near the eye region was touched or from the dorsal surface. When approached dorsally either the eye region or to a lesser extent 
$(<5 \%)$ the abdomen was touched. I positioned myself approximately 0.5-1.0 m either directly behind or directly in front of the web depending on the direction of model presentation to be used. In employing this model the assumption was made that all spiders tested, regardless of instar and species, recognized the model as a predator. Data on construction of barrier webs or "tangles" and the nature of stabilimenta were gathered throughout the summer in an attempt to assess possible anti-predator functions. The chi-square test and Cox and Stuart test for trend were used in the statistical analyses. The taxonomy of Argiope follows Levi ( I968).

\section{The Web}

The orbs of $A$. aurantia and $A$. trifasciata are "typical" araneid webs, consisting of foundation lines, radii, spirals, a free zone and a hub. Neither species constructs a retreat. The spider is normally located at the hub in a head-down position. The web is inclined slightly from the vertical and there may be several stabilimenta bands in or near the hub (fig. I). Up to two barrier webs (fig. 2) may be associated with each orb web.

\section{BARRIER WEBS}

Barrier webs or "tangles" were frequently constructed by $A$. trifasciata and to a lesser extent by $A$. aurantia. Essentially a barrier web is an irregular non-viscid silk mesh connected to the orb web and nearby vegetation or other supports. There can be up to two such tangles, with the primary barrier web positioned behind the dorsum of the spider. The secondary barrier, which is nearly always smaller, is located on the other side of the orb (fig. 2). In early instar $A$. trifasciata the primary barrier web is quite cone-like with the orb forming the base of the "cone". A small gap is left at the bottom of the orb and the cone through which the spider may drop if disturbed. Since these barriers are connected to the outer edge of the orb, disturbances (vibrations) are transmitted to the spider. It is generally thought (Comstock, I948; Gertsch, I949 and Marples, 1969) that they serve some defensive function. My experience with these two species confirms this observation. In paint marking spiders on the dorsum I have often accidentally touched the barrier web, alerting the spider and making it more difficult to mark. In addition to an early warning function, the barrier webs, particularly the primary barrier, constitute a physical obstacle to invertebrate predators. Such barriers reduce the direct points of entry that predators might 
otherwise employ. This is not to suggest that barrier webs are impenetrable; they are easily penetrated, but in the process the occupant is forewarned.

Barrier webs do not act as prey catching structures per se though they may slow down grasshoppers and other relatively strong prey and thereby facilitate capture. Twenty prey items (leaf-hoppers and flies) were tossed onto the primary barrier webs of 20 different $A$. trifasciata. In 19 of 20 cases the prey were either ignored or the spider plucked strands of the orb with no subsequent action. In one instance the prey, a leafhopper, struggled to a point very close to the margin of the tangle and the orb web where it was successfully attacked. In the capture the spider did not completely leave the orb web at any time. Incidental field observations during the summer are in close agreement with the results of this test.

The occurrence of barrier webs changes markedly with the instar of $A$. trifasciata (Table $\mathrm{I}$ ). With the increase in secondary barrier webs, the primary webs are made less cone-like and the mesh progressively coarser. Adult males rarely build complete webs since they generally abandon the web building habit upon reaching maturity and begin the search for females. When the male locates a female or penultimate female web site, he remains on the barrier web until mating can take place. Mating occurs generally within a few days, sometimes within a few hours after the female adult molt. Female

TABLE 1.

Barrier webs and stabilimenta of all field instars of $A$. trifasciata

\begin{tabular}{|c|c|c|c|c|c|}
\hline & Instar & $\begin{array}{c}\text { Number } \\
\text { of } \\
\text { webs }^{1}\end{array}$ & $\begin{array}{l}\text { Primary } \\
\text { barrier } \\
\text { web }\end{array}$ & $\begin{array}{l}\text { Secondary } \\
\text { barrier } \\
\text { web }\end{array}$ & $\begin{array}{c}\text { Stabilimenta: } \\
\text { mean number } \\
\text { bands } / \text { web } \pm \text { S.E. }\end{array}$ \\
\hline & 2 & 300 & 300 & 0 & $0.00 \pm 0.000$ \\
\hline & 3 & 200 & 200 & 0 & $0.00 \pm 0.000$ \\
\hline & 4 & 36 & 36 & 0 & $0.11 \pm 0.053$ \\
\hline & 5 & 20 & 20 & 0 & $0.25 \pm 0.104$ \\
\hline & 6 & 34 & 34 & 1 & $0.38 \pm 0.095$ \\
\hline Juvenile + & 7 & 39 & 39 & 17 & $1.02 \pm 0.107$ \\
\hline Penultimate $\hat{o}$ & 7 & 102 & 102 & 41 & $0.76 \pm 0.064$ \\
\hline Juvenile $ㅇ$ & 8 & 95 & 95 & 48 & $1.40 \pm 0.063$ \\
\hline Penultimate ㅇ & 9 & 39 & 39 & 27 & $1.72 \pm 0.097$ \\
\hline \multirow[t]{2}{*}{ Adult $\$$} & 10 & 29 & 1 & 0 & $0.38 \pm 0.126$ \\
\hline & & 894 & 866 & 134 & \\
\hline
\end{tabular}

${ }^{1}$ Represents minimum number of webs examined with no more than one web/spider counted. 
A. trifasciata virtually cease construction of barrier webs one to two weeks after becoming adults. The omission of barrier webs by mature adult females may relate to the increased size and strength of the female (size increase is quite rapid at this time), to decreased activity of salticids, to the need to maximize food intake before cold weather (both sides of the orb are available as catching surfaces rather than one side or parts of two sides), to nerve degeneration or some other factor(s). No data are available at this time to determine the relative importance of these various factors.

It is interesting to compare the use of barrier webs by the two Argiope species. A. aurantia is the larger of the two and it achieves its larger size in a relatively short time. Larger size probably deters some salticid and other attacks by invertebrate predators. I did not observe such attacks on penultimate and adult $A$. aurantia while they were a frequent occurrence on juvenile $A$. trifasciata at the same time. A. aurantia construct fewer barrier webs and this activity is restricted primarily to the mid-instars. $A$. trifasciata is smaller, matures more slowly and constructs barrier webs throughout most of its life (Table I). Since the primary barrier excludes some prey as well as predators, the inter-relationship between spider size, predator avoidance behavior, food intake and web architecture must be complex. Factors controlling the building of barrier webs need to be determined in order for the niche relations of these two closely related, sympatric species to be properly evaluated.

\section{Stabilimenta}

Stabilimenta, the white zigzag lines of silk which form discrete bands in or near the hub of the orb of several spider species, are a common feature in Argiope webs. These structures vary considerably in form and relative size both between $A$. aurantia and $A$. trifasciata and within each species. Since I found stabilimenta to possess some defensive value to these spiders, their structure and frequency of occurrence are discussed here.

$A$. aurantia build extensive disc-shaped stabilimenta as early and mid-instars (fig. $\mathrm{I}$ ). Up to 7 individual bands were often found in webs but never more than this and usually less (Table 2). A Cox \& Stuart test for trend (Conover, I97I) revealed a significant decrease $(\mathrm{p}<0.05)$ in the number of bands occurring from mid-instar to adult female. This trend is apparent in Table 2. Older spiders construct a thinner "patch" of silk at the hub in place of distinct stabilimenta bands. Adult females make this patch as well as an accompanying linear band below the hub. I also compared adult 
TABLE 2.

Barrier webs and stabilimenta of $A$. aurantia ${ }^{1}$

\begin{tabular}{lccc}
\hline & N & $\begin{array}{c}\text { Mean number of } \\
\text { bands } \pm \text { S.E. }\end{array}$ & $\begin{array}{c}\text { Barrier } \\
\text { webs }\end{array}$ \\
\hline Early \& mid-instars (study area) & 61 & $4.789 \pm 0.218$ & 9 \\
Penultimate \& adult $\$$ 's (study area) & 28 & $2.429 \pm 0.196$ & 0 \\
Older adult 's (study area) & 29 & $1.828 \pm 0.100$ & 0 \\
Older adult + 's (Knox Co., Tenn.) & 50 & $1.740 \pm 0.085$ & 0 \\
\hline
\end{tabular}

1Thin "patch" was not assigned a value and thus was not used in calculations.

female webs in my study area to those of a population near Stock Creek Boat Dock in Knox County, Tenn. The results of a t-test showed no significant difference $(\mathrm{p}<0.05)$ in the number of bands in these two populations. It is interesting that Reed, et al., (1969) found "no obvious pattern or change in complexity" in laboratoryreared $A$. aurantia. Whether this difference is due to selection pressures or possibly some cue(s) existing in field situations that do not exist in the laboratory is not known.

The stabilimenta of $A$. aurantia can conceal the spider. Concealment of the spider's state (especially when molting) is probably advantageous. Both Argiope species molt at the hub during the day and are completely defenseless during this process. Concealment of the true size of the spider may also be a deterrent to the invertebrate predator since larger orb weavers can ward off and maybe even kill a smailer attacker. It is even possible that stabilimenta conceal attackeliciting stimuli from certain predators.

$A$. trifasciata constructed substantially fewer bands in their webs than $A$. aurantia (Tables I \& 2). A Cox \& Stuart test for trend indicated a significant increase $(\mathrm{p}<0.05)$ in the number of bands with instar of $A$. trifasciata (2O individuals of each instar were selected at random prior to testing). These results differ from Comstock ( 1948) who found that juvenile $A$. trifasciata built extensive disc-shaped stabilimenta. The reasons for these differences are not known, but I suspect that extensive use of barrier webs and the increase in stabilimenta bands may be related to heavy predation pressure by salticids.

Stabilimenta can also function as physical shields. The heavy silk bands reinforce the hub and make direct penetration more difficult. This is readily demonstrated by forcing a pencil or similar object through the hub of webs with and without such stabilimenta. 


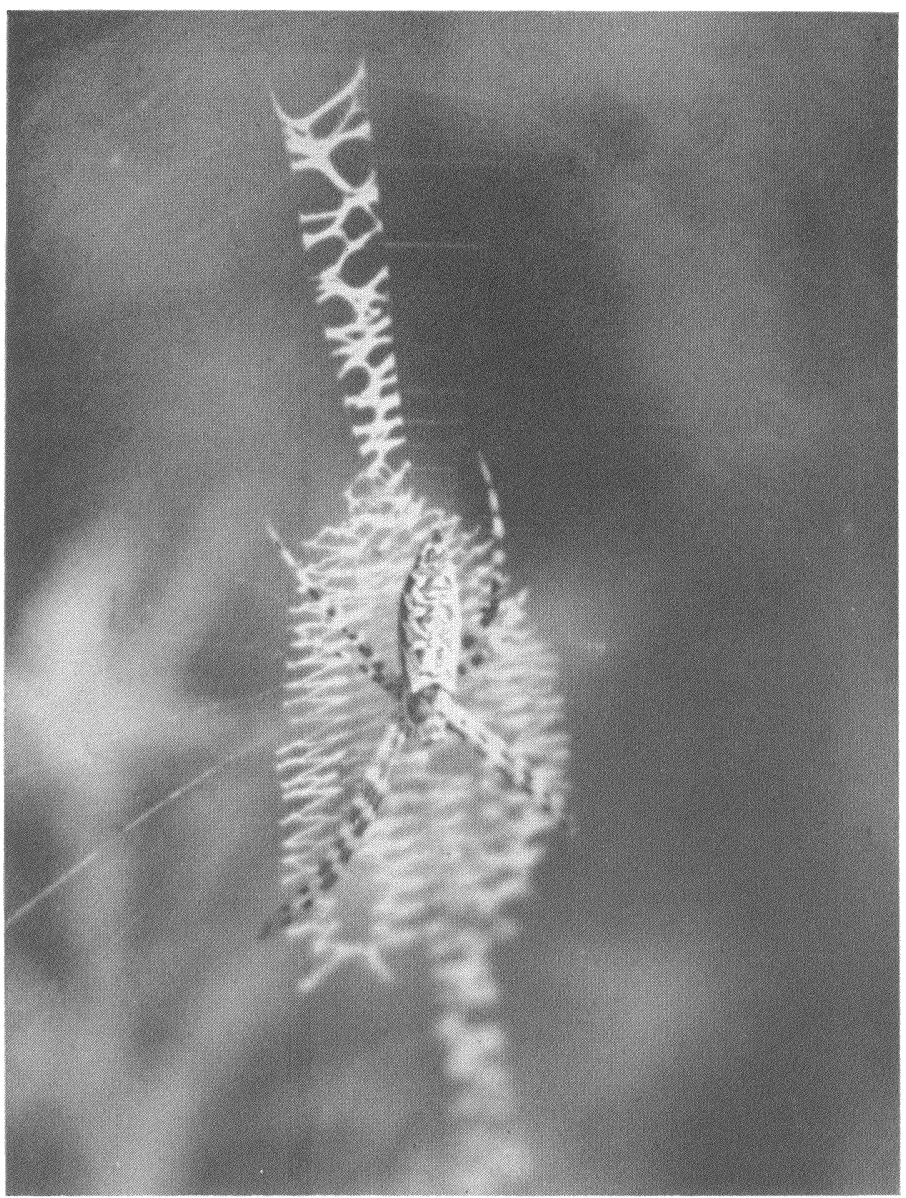

Figure 1. Argiope aurantia and its stabilimentum. Note light color of spider. 


\section{Predator Avoldance Components}

All descriptions of predator avoidance components apply equally to $A$. aurantia and $A$. trifasciata. There are differences in relative usage of these components (discussed in next section) and their combination in behavioral sequences.

Web Flexing

Web flexing is accomplished when the spider sets the web in motion along its short axis by rapid extension and retraction of the legs. Spider and web thus swing back and forth parallel to the ground surface, since the long axis of the web is oriented more or less perpendicular with respect to the ground. Web flexing adds another dimension to the predator's attempt at attack, that of motion. Obviously, contact is more difficult to establish and maintain when the spider and web are in motion. In one encounter of a salticid and an

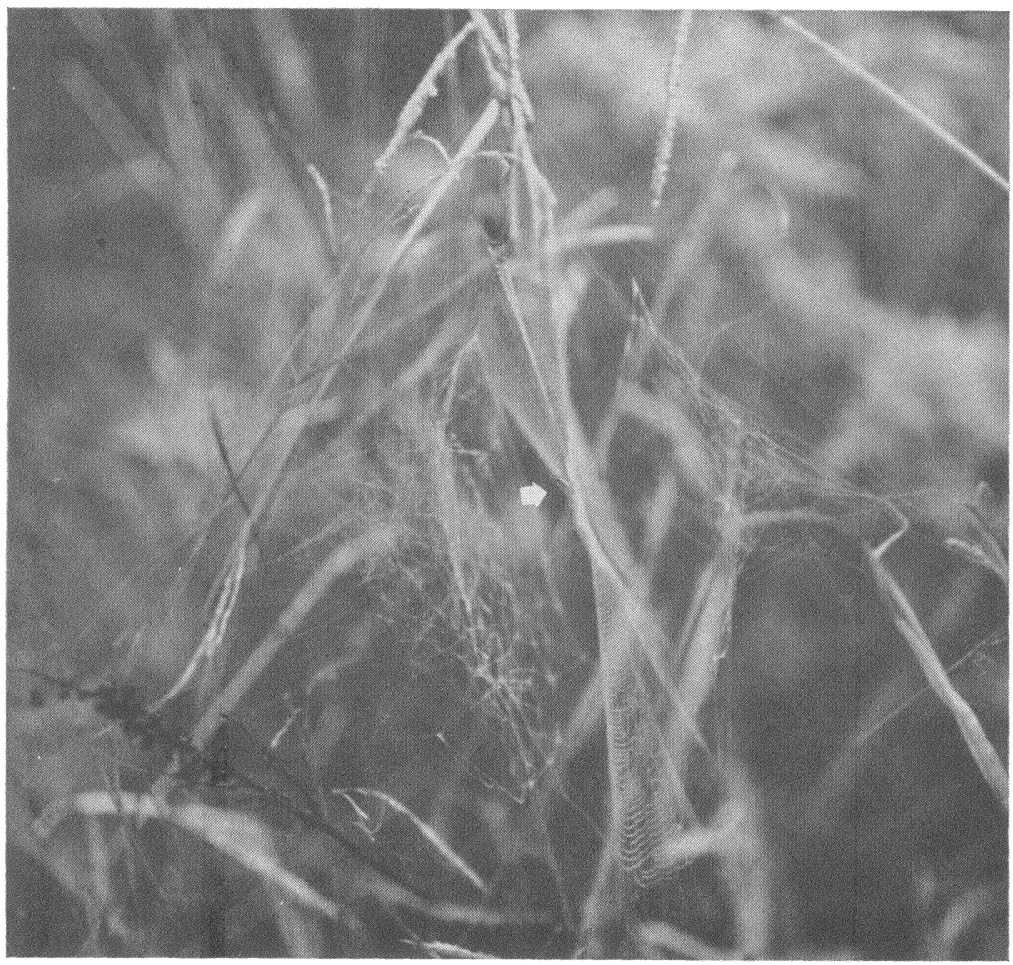

Figure 2. Juvenile $A$. trifasciata with barrier webs. Note primary barrier behind dorsum of the spider; arrow is pointing to spider's dorsum. 
A. aurantia, the salticid lost its grip on the Argiope's web and body (?) after web flexing was commenced; the salticid (a juvenile $P$. audax) fell onto the sticky spirals of the orb weaver's web where it became entangled and was treated as a prey item (i.e. wrapped, bitten and fed upon). Web flexing might also distract the potential predator and temporarily conceal the exact location of the orb weaver.

\section{Stilting}

Stilting results when the spider straightens all four pairs of legs and thus moves the sternum and venter further away from the hub surface (fig. 3). The abdomen is often tilted dorsally as well; the spider when viewed from the ventral side appears smaller because of the reduced surface area exposed. This response might also change the sign stimulus to a shape the predator does not readily recognize (Riechert, personal comm.), but additional testing will be required before this is known.

\section{Dropping from web}

Dropping or jumping from the web rarely occurred in the testing. During the trials it was never followed by leaving the web site though I have observed this behavior in certain field situations. When a web is approached rapidly and it or the vegetation to which it is attached is severely disturbed, the spider may jump from the web and actively leave the site. When dropping or jumping from the web did occur under test situations and when it was normally observed in the field, a dragline was secured to the hub before the spider dropped into the vegetation. Spiders then took up a position underneath a blade of grass, a leaf or along a plant stem where they remained for periods of less than one minute to over an hour ( $A$. aurantia $\mathrm{N}=6, \overline{\mathrm{x}}$ time $=3$ min. 02 seconds; $A$. trifasciata $\mathrm{N}=35$, $\overline{\mathrm{x}}$ time $=3 \mathrm{~min}$. I I seconds). Return to the hub was always via a direct, rapid climb up the dragline to the hub where a head-down position was assumed. If the vegetation near the spider or the spider itself was touched it immediately went back to the hub. Leaving the web is certainly an escape response and hiding underneath the vegetation is probably best applied against visual predators. Rapid return to the hub, especially when the vegetation is lightly disturbed, would facilitate escape if the predator was no longer in visual contact. Returning directly to the hub immediately places the spider at the center of its web. This may be advantageous since the orb weaver is back at the center of its auxiliary information gathering system, the web, and because most predator avoidance options are available at the hub. 


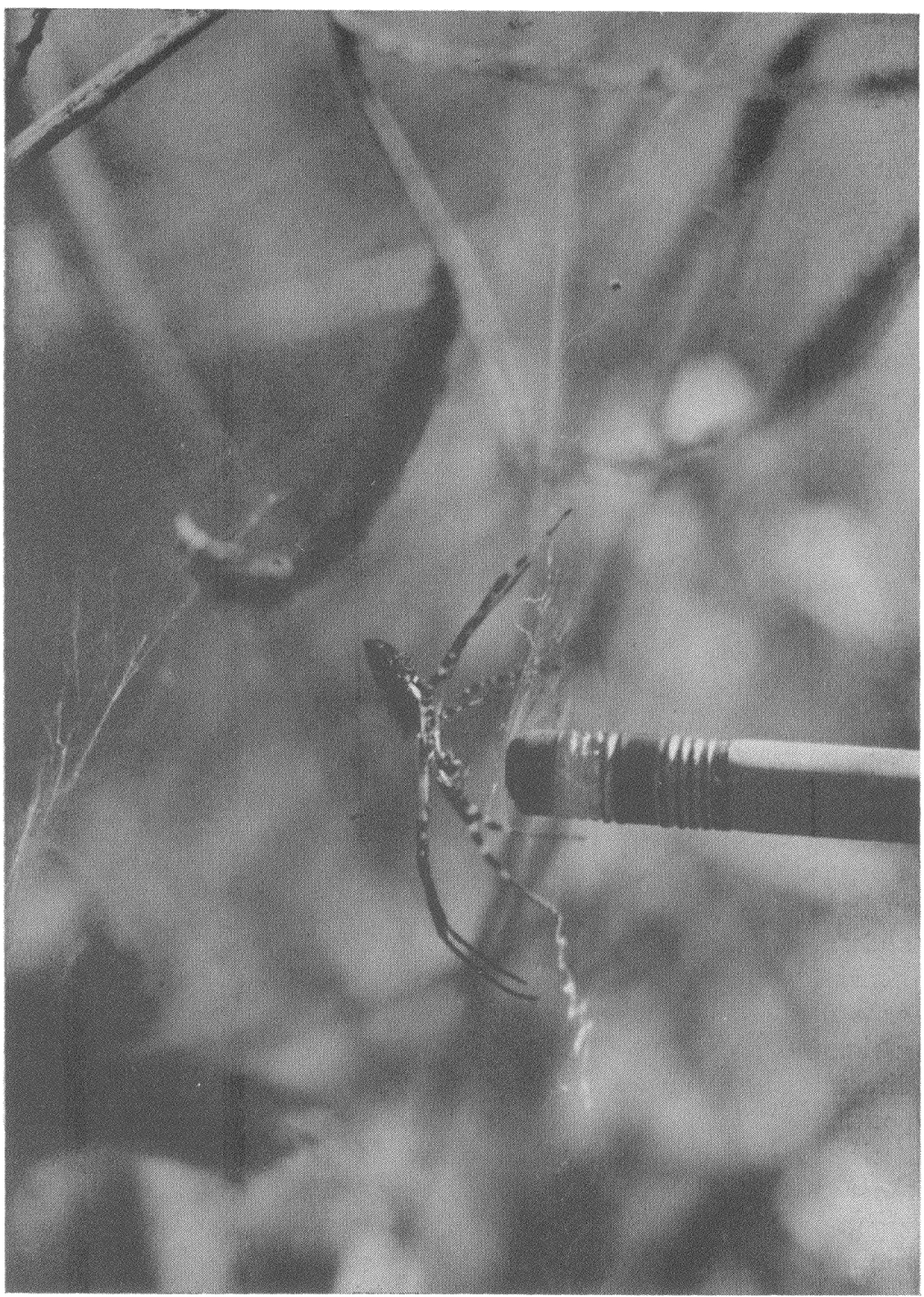

Figure 3. Argiope trifasciata stilting. Note extension of legs and distance of body away from hub surface. 


\section{Switching sides of the web}

Switching sides of the web is accomplished when the spider moves between the radii in the "free zone" to the other side of the hub. It may be followed by web flexing, stilting, or web flexing later followed by stilting (fig. $4 \mathrm{~B}$ ). This response results in the interposition of the web as a physical barrier between the orb weaver and a potential predator.

\section{Moving away from hub}

When moving away from the hub the spider moves directly away from the point of contact: when its eye region is touched, the spider moves up the web and if the abdomen is touched, it moves down the web. Although one component was often immediately followed by another in a single response sequence, individual components were usually easy to identify. One exception is when the spider leaves the hub while simultaneously flexing the web; it is often impossible to tell which is the initial response. In statistical analyses and graphic presentations (figs. 4, 5 and 6) web flexing is treated as the initial response. This particular behavioral sequence is unusual in another way. Generally web flexing was initiated by rapid spider movement which resulted in considerable web movement and a large amplitude of web displacement. The response gradually subsided with web amplitude decreasing as web and spider movement slowed. In the hub leaving-web flexing sequence, however, the spider sometimes slowly returned to the hub while web flexing continued. Upon reaching the hub or shortly thereafter all motion quickly ceased. An observer has to watch closely to detect spider movement toward the hub; this behavior probably serves to distract the predator and then hide the orb weaver.

Rebuff

Rebuff, as used here, should not be confused with elements of the predatory behavior of these species (see Harwood, I974). It is here defined as actively repulsing (pushing away) the model by using any of the legs of pairs I or II and/or briefly grasping the model with these legs. Biting was never observed although chelicerae were sometimes opened and fangs exposed. This may be an intention movement and/or threat posture.

\section{Body flatten}

In a few instances when spiders were approached dorsally, they would simply depress their bodies away from the model and flatten against the hub. 


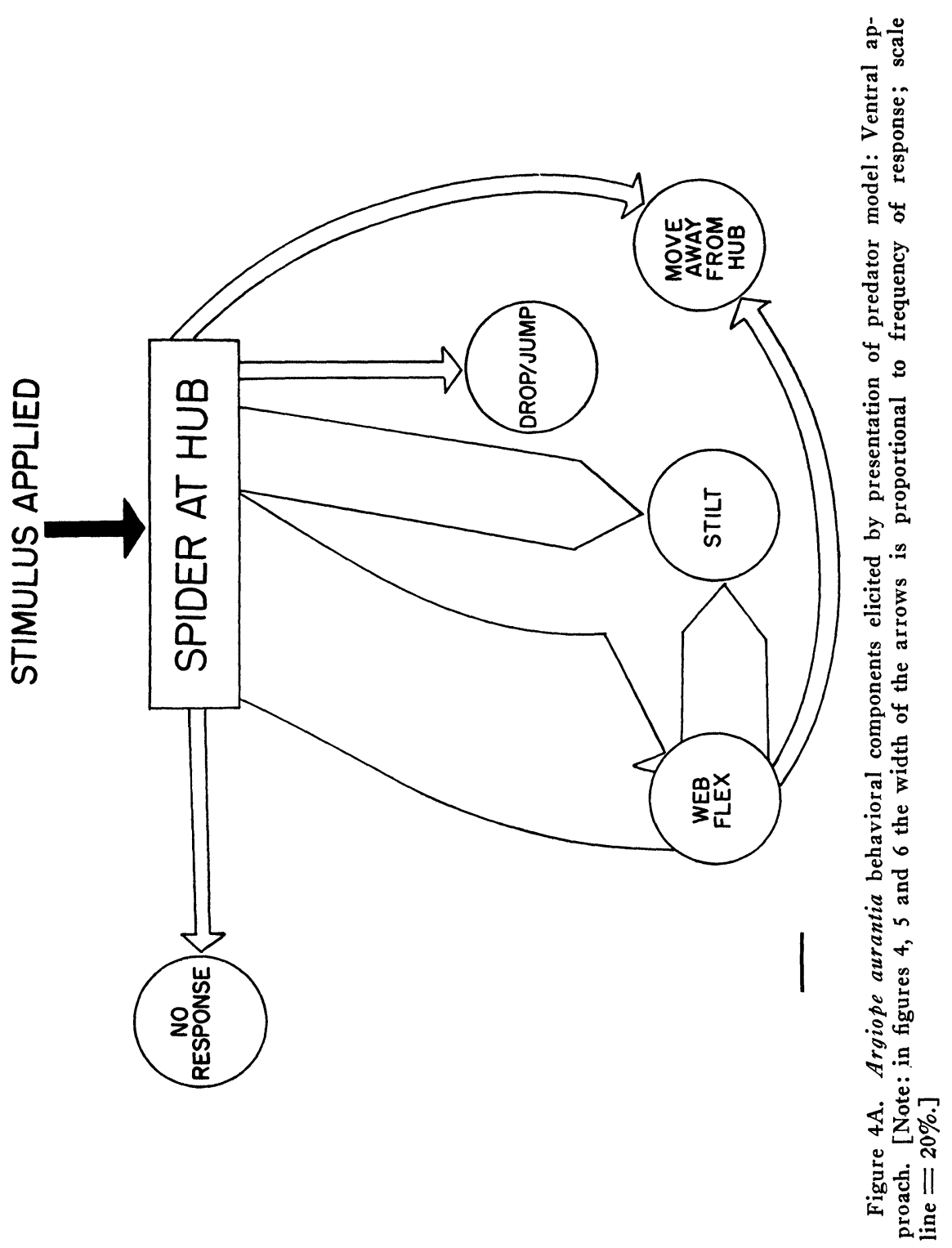




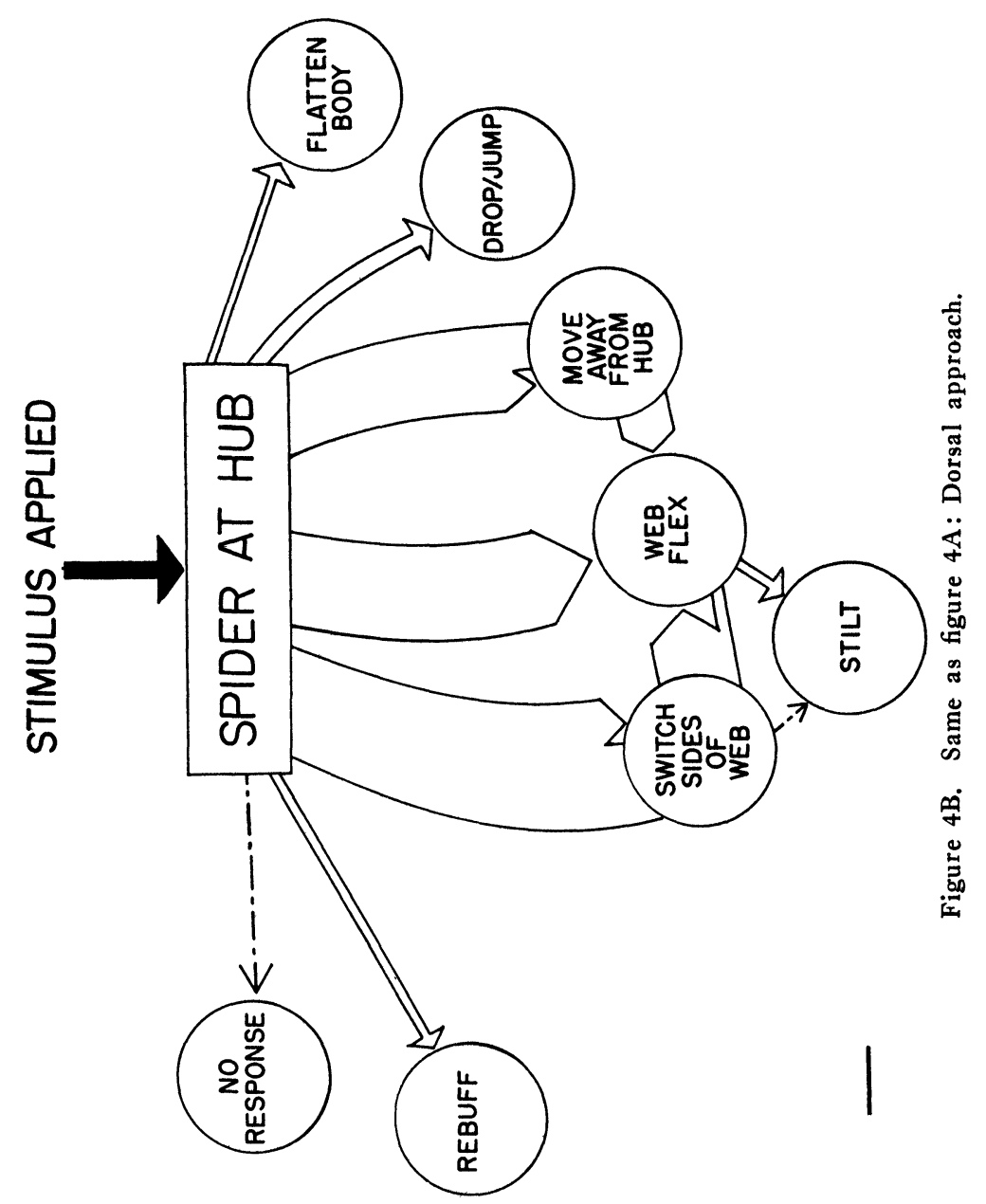




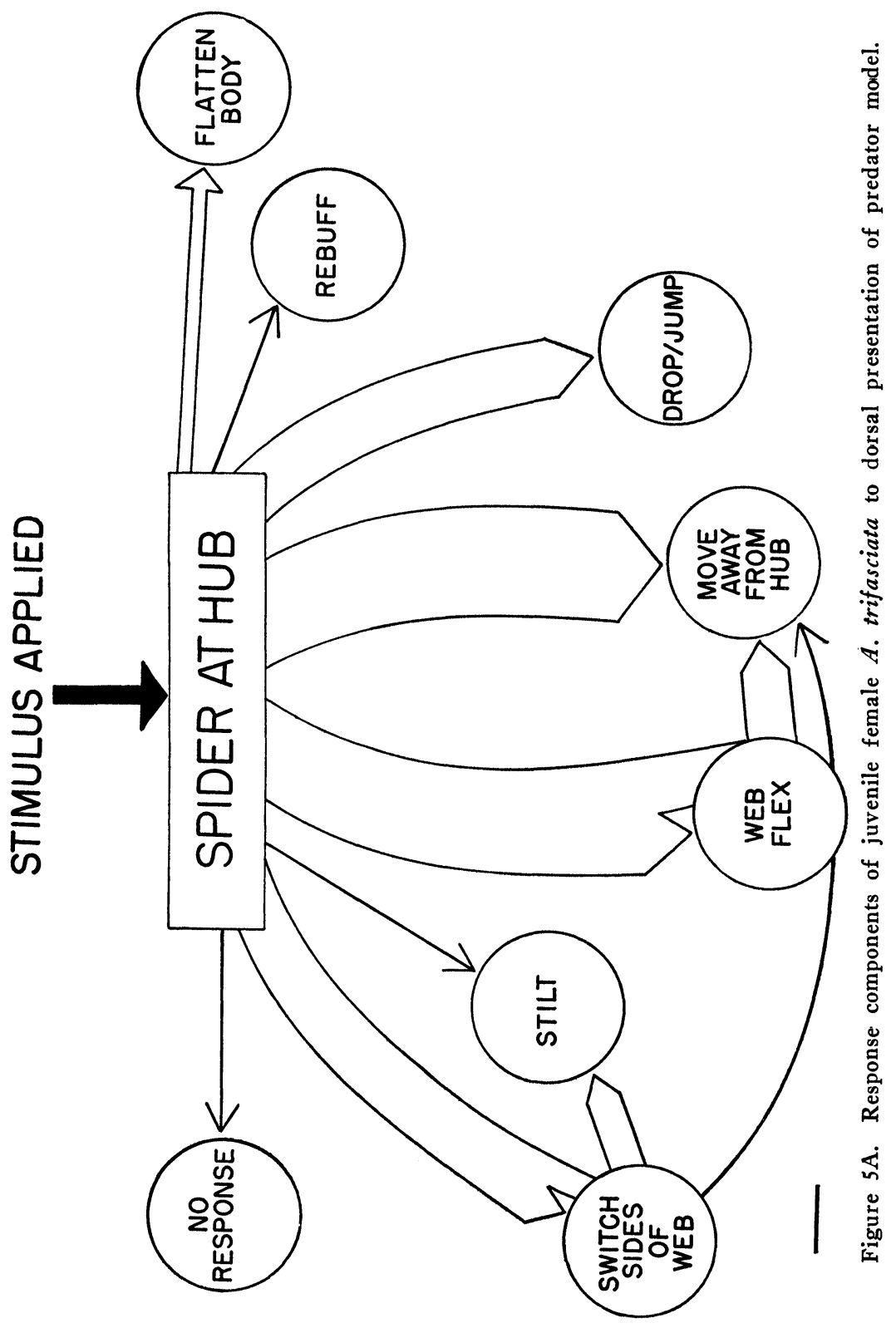




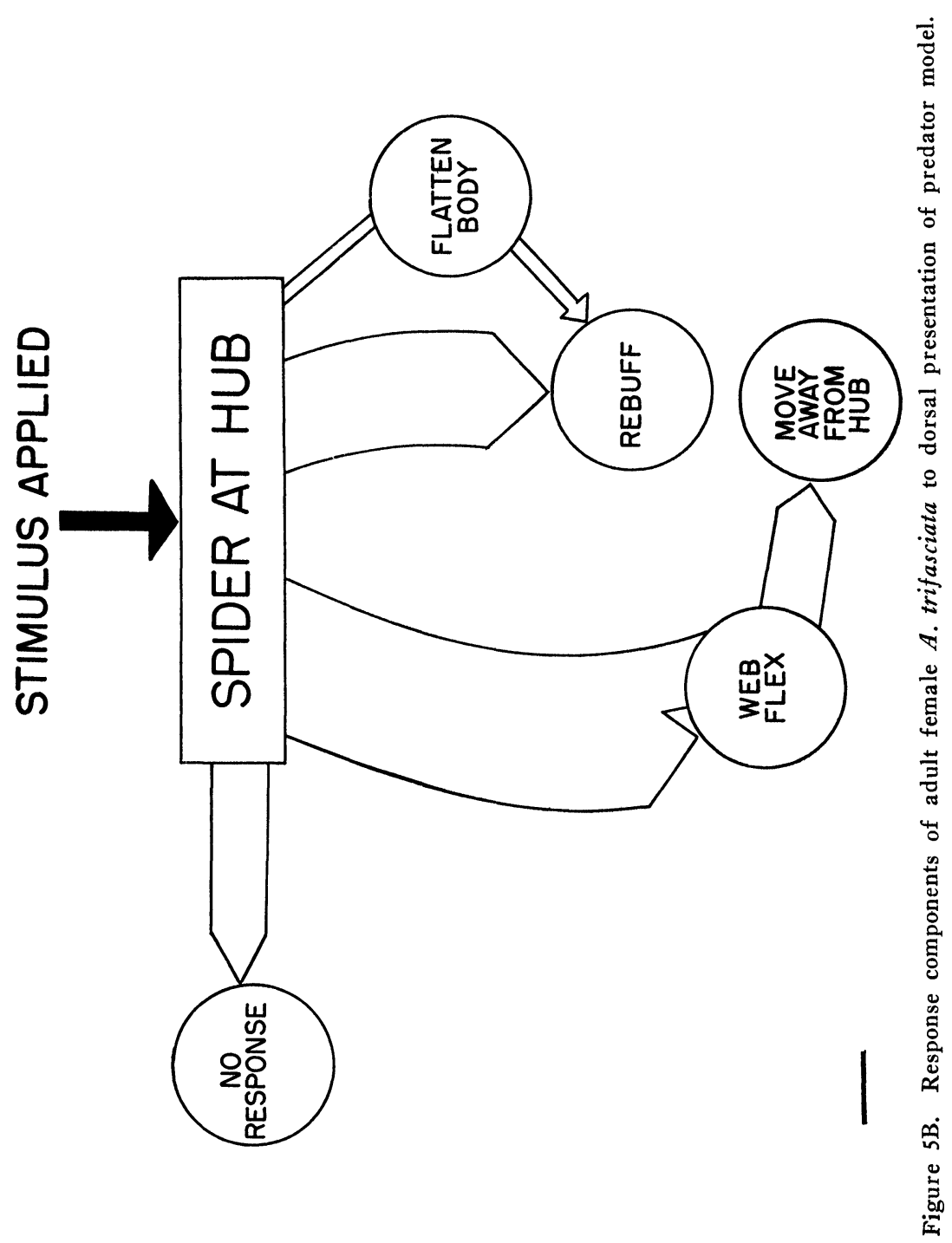




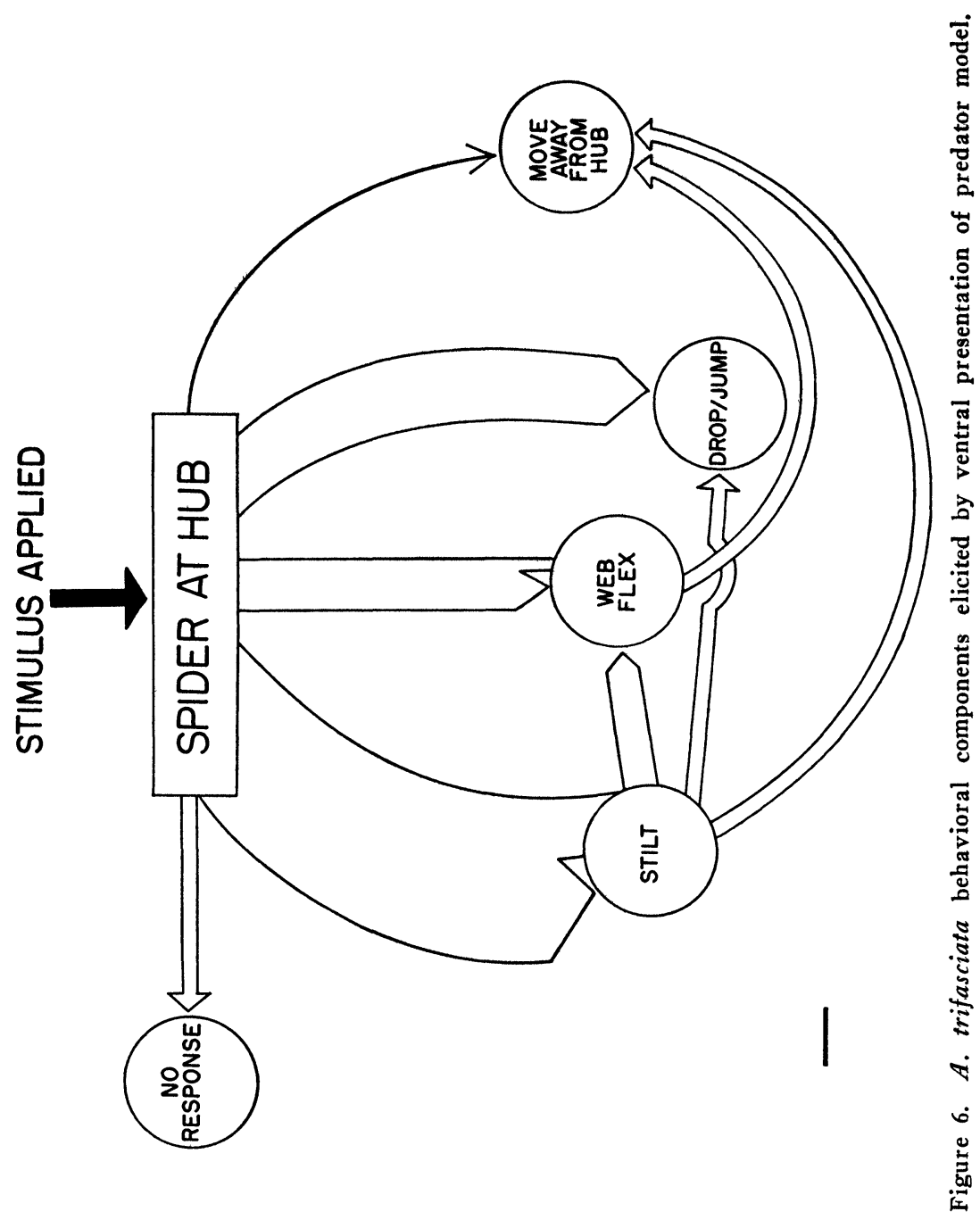


At times no response was observed even with repeated presentation of the model.

\section{Differences in Component Use}

Any insect or arachnid that approaches an orb web falls into one of four categories: (I) potential prey, (2) potential predator or parasite, (3) potential mate and (4) "neutral" (unpalatable prey, too large or strong an animal for the spider to subdue, etc.). An orb weaver that responds incorrectly may fail to obtain sufficient food, may be killed or may fail to mate. While this study does not identify the specific cues involved in these decisions, one would not expect all spiders of the same species or the same individual at different times to respond identically to a standard stimulus. The various response components are analyzed below under a variety of conditions to delineate their use.

\section{Dorsal vs. ventral model presentation}

$A$. aurantia and $A$. trifasciata were tested separately for differences in response components elicited by dorsal vs. ventral presentations of the simulated predator. A chi-square test (Conover, 197I) was employed in the analyses and unless otherwise stated this is the test used throughout the paper. The response of $A$. aurantia differed significantly $\left(n=94, x^{2}=41.23, p<0.001\right)$ with dorsal and ventral presentations (fig. 4). Stilting and web flexing followed by stilting accounted for over 50\% of the above variability. They occurred with substantially greater frequency than expected when the model was presented ventrally. Switching sides of the web followed by web flexing occurred more often than expected on dorsal presentations. A trifasciata also exhibited a significant difference $\left(\mathrm{n}=\mathrm{I} 8 \mathrm{I}, \mathrm{x}^{2}=102.84, \mathrm{p}<0.001\right)$ in response components. Stilting again proved to be primarily a response to ventral presentations of the model. Web flexing, moving away from the hub and rebuff occurred much more often than expected when spiders were touched dorsally (figs. 4 and 5). It should be mentioned that the majority of responses $(>95 \%)$ occurred after the model touched either the web or the spider with less than $5 \%$ occurring on the actual approach. Due to the small number of responses to the actual approach of the simulated predator these data are included, without distinction, in the various statistical tests. Also, the term "presentation" refers to both approach and touch responses. 
aurantia vs. trifasciata

The responses of $A$. aurantia and $A$. trifasciata to dorsal presentations and of $A$. aurantia and $A$. trifasciata to ventral presentations were analyzed separately. The two species differed significantly $\left(\mathrm{n}=\mathrm{I} 38, \mathrm{x}^{2}=33 . \mathrm{I}, \mathrm{p}<0.005\right)$ from one another in their respective responses to dorsal presentations of the simulated predator. Switching sides of the web and this component followed by web flexing occur more frequently in $A$. aurantia than $A$. trifasciata. $A$. trifasciata either failed to respond or rebuffed the model with greater frequency than expected (compare figs. $4 \mathrm{~B}$ and $5 \mathrm{~B}$ ). Responses to ventral presentations of the model were also significantly different $\left(\mathrm{n}=\mathrm{I} 38, \mathrm{x}^{2}=38.3, \mathrm{p}<0.005\right)$ for the two species. Differences in web flexing accounted for over $75 \%$ of this variability and differences in this component alone were sufficient to produce a significant difference $(\mathrm{p}<0.005)$ between the responses of the two species. $A$. aurantia web flexed significantly more often than $A$. trifasciata.

\section{Component differences of instars}

Since behavioral responses may change with the age or instar of the spider due to maturation, learning, perceptual abilities or other factors, juvenile instars 4,5 and 6 and adult female (instar Io) A. trifasciata, were examined for possible differences in predator avoidance. When the simulated predator was presented dorsally there was a significant difference $\left(n=61, x^{2}=41.4, p<0.005\right)$ in response components. Dropping and moving away from the hub were primarily juvenile responses while rebuff and failure to respond were adult responses (fig. 5). Juvenile responses also contained more components than adult responses. It should be noted that adult female $A$. trifasciata are large enough to ward off the salticid species common in the area, since the salticid populations are primarily represented by eggs and juveniles at this time; male salticids have died and females spend much of their time guarding eggsacs and young. This may account for some of the differences observed. Data were insufficient to compare ventral presentations statistically, but the relative frequencies of occurrence of various components are shown in fig. 6 .

Both species are thus capable of a broad array of responses that enable them to escape predation on their relatively exposed webs. These responses may also be important in avoiding predatory wasps and other predators and parasites. It is not claimed that the responses discussed here represent the complete repertoire of the two species. 
As previously mentioned, leaving the web site does occur in some instances. I have also observed "death feigning" by one adult female A. aurantia when I rapidly approached her web. The individual dropped into the vegetation and all legs were drawn in close to the body. The spider's venter was exposed as it lay on its back and the spider remained motionless for several minutes. No color change such as that reported for Gea heptagon (Hentz) (Sabath, I969) was detected.

\section{ResPonse Threshold}

The response threshold is operationally defined here as the number of stimulus applications (model presentations) needed to elicit a response of any kind (one component or a sequence of components) by the spider. If Io stimulus applications failed to produce a response, "no response" was recorded.

\section{Dorsal vs. ventral model presentations}

Intuitively it would seem that a spider approached from the ventral side would be safer from predators since the web constitutes a physical barrier. Response threshold, in addition to response components, thus might differ with orientation of model presentation. When this parameter was tested for $A$. aurantia and $A$. trifasciata, they exhibited significantly different response thresholds to ventral vs. dorsal presentations of the model ( $A$. trifasciata $\mathrm{n}=\mathrm{I} 89, \mathrm{x}^{2}=\mathrm{I}$ I. I, $\mathrm{p}<$ $0.05 ; A$. aurantia $\left.\mathrm{n}=95, \mathrm{x}^{2}=\mathrm{I} 7.2, \mathrm{p}<0.005\right)$. Both species were more responsive to the dorsal than the ventral model presentations.

aurantia vs. trifasciata

I found no significant difference in response thresholds $(n=284$, $\mathrm{x}^{2}=$ I0.5, $\mathrm{p}<0.05$ ) between the two species. Thus, while predator avoidance behaviors are utilized to different extents, the readiness to respond apparently does not differ in these two species.

\section{Age differences}

A. trifasciata instars $4,5,6,7$ and adult females were tested for differences due to age. No significant difference $\left(\mathrm{n}=176, \mathrm{x}^{2}=\right.$ $48.8, \mathrm{p}<0.05)$ among instars was revealed.

\section{Differences to repeated model presentations}

Finally I wanted to know if there were differences in the response thresholds in individuals undergoing successive trials. I applied four series of model presentations to the same individual with a 30 second pause at the end of each response sequence. There was no significant 
difference in either $A$. aurantia $\left(\mathrm{n}=\mathrm{I} 8\right.$ spiders, $\mathrm{x}^{2}=5.04, \mathrm{p}<$ 0.05 ) or $A$. trifasciata ( $\mathrm{n}=8$ spiders, $\mathrm{x}^{2}=4.03, \mathrm{p}<0.05$ ) for dorsal or ventral model presentations. The spiders apparently exhibited neither habituation to the stimulus nor increased sensitivity under these test conditions.

\section{ResPonse DURATION}

Since the duration of several response components could vary with the particular test situation, I analyzed the variability of the web flexing response in this context since it is an easily measured component. Response levels were grouped into four categories: O-IO, II-3O, 3I-I 20 and $>$ I 20 seconds. These levels were chosen such that the expected values would be large and the test thereby more rigorous (Conover, 197I). Response duration of web flexing to dorsal vs. ventral presentations of the model were not significantly different $(\mathrm{p}<0.05)$ for either $A$. aurantia $(\mathrm{n}=56)$ or $A$. trifasciata $(\mathrm{n}=45)$. The mean web flexing duration was $39.7 \mathrm{I} \pm 10.52$ and $44.27 \pm 12.72$ seconds respectively, for the two species. Thus the apparent variability existed in the ranges of response duration, but was not associated significantly with the test situation.

\section{Discussion}

In this study, barrier webs and stabilimenta were found to complement the predator avoidance behaviors of $A$. aurantia and $A$. trifasciata. It is interesting that these two closely related species with sympatric populations should also employ barrier webs and stabilimenta to such markedly different extents. Recall that $A$. aurantia switched sides of the web with much greater frequency when approached dorsally or touched on the dorsum than $A$. trifasciata. This behavioral difference may be related to the more extensive use of stabilimenta by this species. A . trifasciata, on the other hand, has a thinner hub which more easily permits viewing the spider, and use of other predator avoidance behaviors or web structures, such as barrier webs, may better enhance survival. It is also noteworthy that $A$. aurantia web flexed to a significantly greater extent when the simulated predator was presented ventrally than $A$. trifasciata. Web flexing, in addition to adding motion to the potential predator's attack problem, might give the stabilimentum some shock value. Web flexing and the stabilimentum may act synergistically as a threat stimulus. Salticids are known to respond to a wide variety of shapes and patterns (models) as though they were prey items. If the models 
are not distinguished as other salticids, then they are considered potential prey, with size of the prey being the primary discriminant (Drees, I952 as reported by Land, I972). Since the stabilimentum can conceal the spider's size by obscuring its outline (fig. I) and if salticids do respond to the stabilimentum or parts of this structure rather than the orb weaver when web flexing is commenced, it is easy to see how a threat stimulus situation could arise. Of course, web flexing would rapidly change the apparent size of the stabilimentum and in some instances the spider also. This may explain why $A$. aurantia with their extensive stabilimenta web flex more when approached ventrally than $A$. trifasciata. The differences in $A$. aurantia and $A$. trifasciata are more easily understood when elements of web architecture are also considered.

The diversity of orb weaving species is immense and has already been discussed, but the variability in the structure of orb webs is also extensive (Levi, I974). I believe considerable insight into spider defensive strategies can be gained by comparison of web architecture, predator avoidance behaviors and predation pressures in this and other spider genera. It may be more than coincidental that species of six genera (Argiope, Cyclosa, Gasteracantha, Gea, Nephila and Uloborus) known to construct stabilimenta or other web decorations are diurnal. Of course one way in which a stabilimentum might function to conceal a spider is for it, rather than the spider, to be conspicuous and daylight is presumably necessary for a stabilimentum to be visible. This is not to say that stabilimenta in different species function in precisely the same manner or that they might not possess other functions but diurnality for these six genera is a striking fact. Neither do these species build identifiable retreats which could provide some measure of protection from predators. Several species, particularly in the genus Argiope, are also a silver color which would tend to blend with a stabilimentum. $A$. aurantia and $A$. trifasciata individuals undergo color change during their lives and are silvercolored when stabilimenta are extensive.

\section{SUMMARY}

The orb weavers $A$. aurantia and $A$. trifasciata utilize numerous behavioral responses complemented by both barrier webs and stabilimenta as defenses against predation. Barrier webs alert the spider to the presence of a potential predator; primary barrier webs are constructed by all instar $A$. trifasciata except older adult females. $A$. aurantia build fewer such structures. Stabilimenta function to con- 
ceal the orb weaver and when the spider web flexes the stabilimentum may become a threat stimulus. $A$. aurantia construct more extensive stabilimenta than $A$. trifasciata.

Web flexing, stilting and web flexing followed by stilting predominate as responses to ventral presentations of a simulated predator. Switching sides of the web, web flexing, switching sides followed by web flexing and moving away from the hub are main responses to dorsal presentations. Predator avoidance components are used differentially by the two species for both dorsal and ventral model presentations, by each species for dorsal vs. ventral model presentations and by various instars of one species, $A$. trifasciata. Juvenile responses contain more components than adult responses and adult female $A$. trifasciata are more prone to rebuff or ignore the model than juveniles. Response thresholds differ significantly only with dorsal vs. ventral presentations of a simulated predator for both species. No significant differences in response thresholds exist between species and among instars of a species. Neither species becomes habituated or more sensitive to repeated model presentations. Web flexing response duration is not significantly different for either species when the simulated predator is presented dorsally vs. ventrally. Behavioral components and web architecture are believed to work together in the defensive strategies of these two orb weaving species.

\section{REFERENCES}

BRISTOWE, W. S.

1941. The comity of spiders, Vol. II. Johnson Reprint Corp., New York. Сомттоск, J. H.

1940. The spider book. Rev. edit. Comstock Publishing Co., Inc., Ithaca, New York.

Conover, W. J.

1971. Practical nonparametric statistics. John Wiley \& Sons Inc., New York.

DORRIS, P. R.

1970. Spiders collected from mud-dauber nests in Mississippi. J. Kansas Entomol. Soc. 43 : 10-11.

Eberhard, W.

1970. The predatory behavior of two wasps, Agenoideus humilis (Pompilidae) and Sceliphron caementarium (Sphecidae), on the orb weaving spider Araneus cornutus (Araneidae). Psyche 77: 243251.

EIBL-EIBESFELDT, I.

1970. Ethology: The biology of behavior. Holt, Rinehart and Winston, New York. 
ENDERS, F.

1974. Vertical stratification in orb-weaving spiders (Araneidae, Araneae) and a consideration of other methods of coexistence. Ecology $55: 317-328$.

GerTSCH, W. J.

1949. American spiders. D. van Nostrand Co., Inc., Princeton.

Harwood, R. H.

1974. Predatory behavior of Argiope aurantia (Lucas). Amer. Midland Natur. $90: 130-139$.

KASTON, B. J.

1964. The evolution of spider webs. Amer. Zool. 4: 191-207.

1966. Evolution of the web. Natural History 75: 27-32.

KurCZEWsKr, F. E.

1963. Some new pompilid prey records from southern Florida (Hymenoptera: Pompilidae). Fla. Entomol. 46: 209-213.

KurCZEWSKI, F. E. AND E. J. KURCZEWSKI.

1968a. Host records for some North American Pompilidae (Hymenoptera) with a discussion of factors in prey selection. J. Kansas Entomol. Soc. $41: 1-33$.

1968b. Host reconds for some North American Pompilidae (Hymenoptera) First supplement. J. Kansas Entomol. Soc. 41: 367-382.

LAND, M. F.

1972. Mechanisms of orientation and pattern recognition by jumping spiders (Salticidae), pp. 231-247. In Symposium on Information Processing in the Visual Systems of Arthropods. R. Wehner, Ed. Springer-Verlag, Berlin.

Levi, H. W.

1968. The spider genera Gea and Argiope in America (Araneae: Araneidae). Bull. Museum Comp. Zool. 136 (9): 319-352.

1974. Talk given to Amer. Arach. Soc. Meeting, Lynchburg, Va., August, 1974.

Levi, H. W. and L. R. Levi.

1968. A guide to spiders and their kin. Western Publishing Co., New York.

Marples, B. J.

1969. Observations on decorated webs. Bull. British Arachn. Soc. 1: 13-18.

Muma, M. H. AND W. F. JefFers.

1945. Studies of the spider prey of several mud-dauber wasps. Ann. Entomol. Soc. Amer. 38 : 245-255.

Reed, C. F., P. N. Witt and M. B. Scarboro.

1969. The orb web during the life of Argiope aurantia (Lucas). Developmental Psychobiol. $2(2)$ : 120-129.

Robinson, M. H. And B. Robinson.

1970. The stabilimentum of the orb-web spider Argiope argentata: An improbable defense against predators. Canad. Entomol. 102: 641-655.

1973. Ecology and behavior of the giant wood spider Nephila maculata (Fabricius) in New Guinea. Smithsonian Contr. Zool. 149: 1-76. 
ROYama, T.

1970. Factors governing the hunting behavior and selection of food by the Great Tit (Parus major L.). J. Anim. Ecol. 39: 619-668.

Sabath, L. E.

1969. Color change and life history observations of the spider Gea heptagon (Araneae; Araneidae). Psyche 79: 367-374.

SAVORY, T.

1964. Arachnida. Academic Press, London.

Tinbergen, N.

1969. The study of instinct. Oxford Univ. Press. Oxford. 

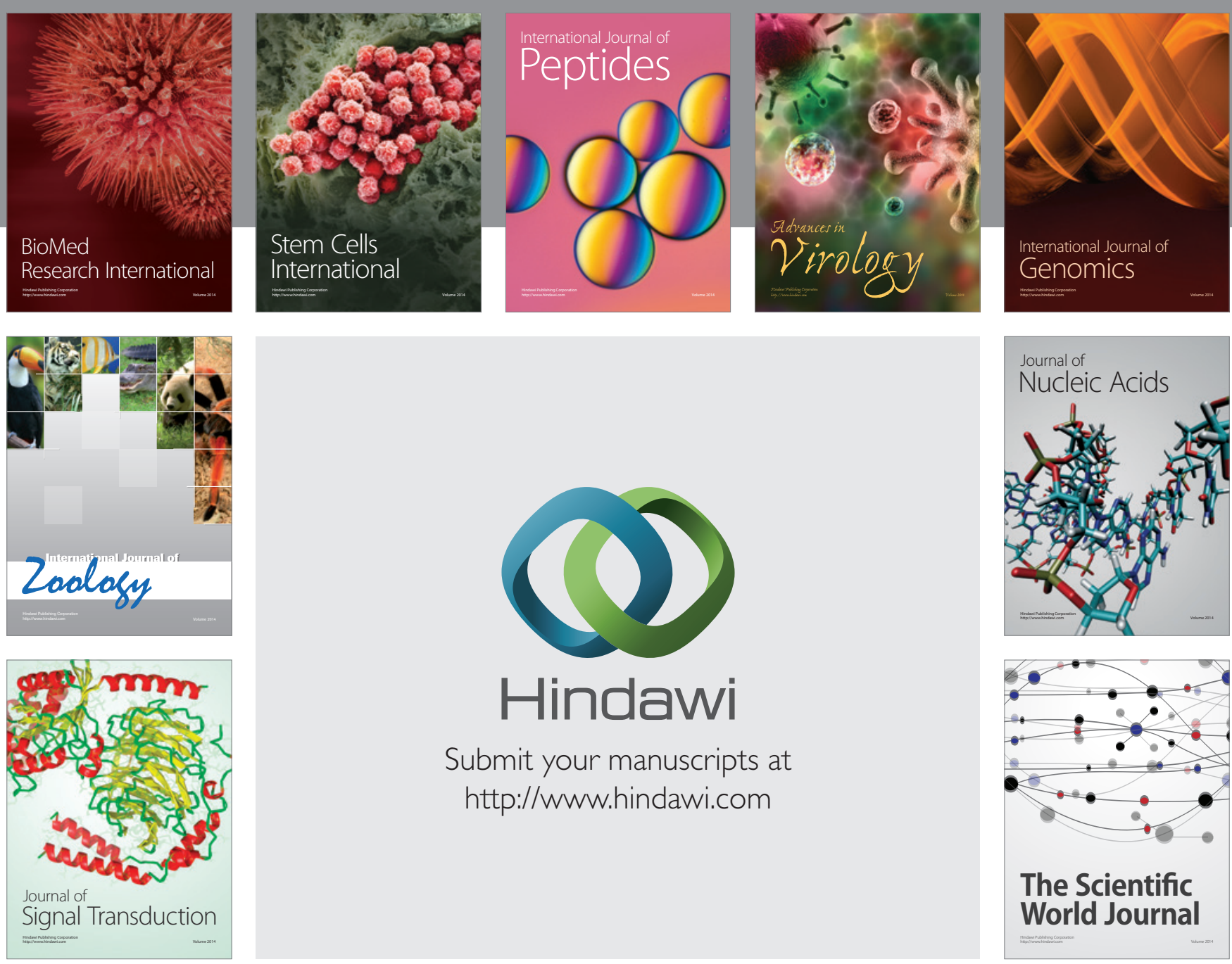

Submit your manuscripts at

http://www.hindawi.com
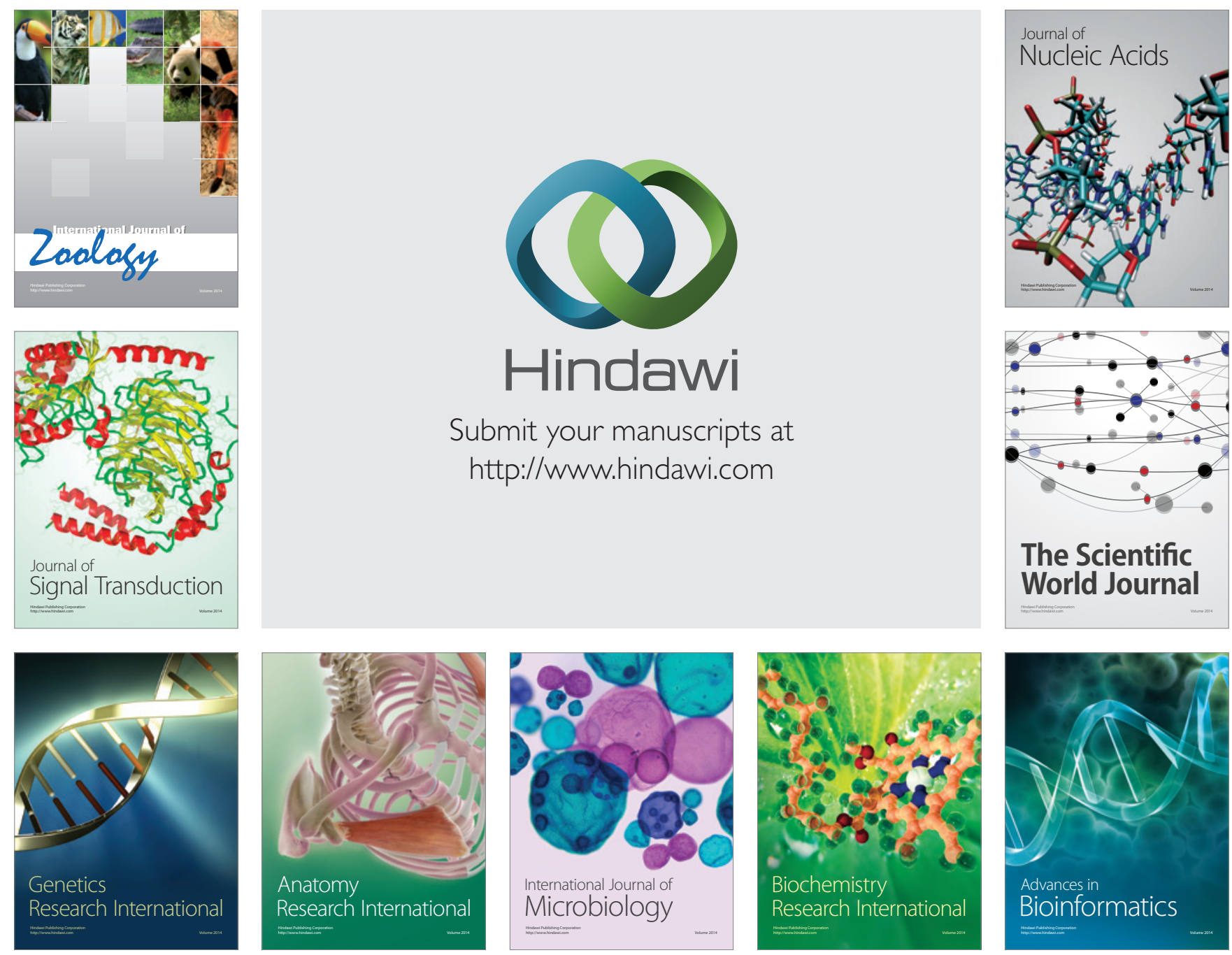

The Scientific World Journal
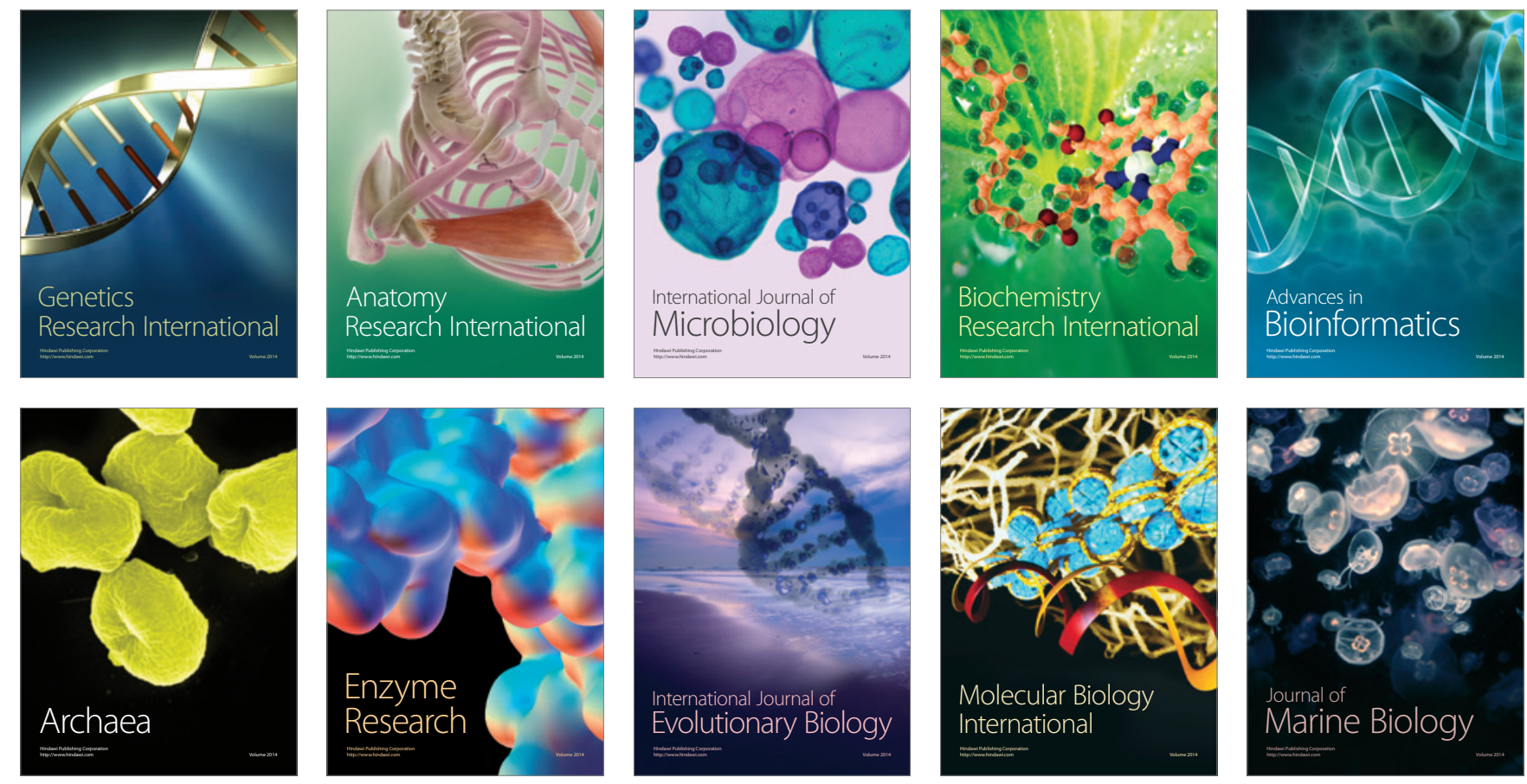